\title{
At work in the field: problems and opportunities associated with employment during fieldwork
}

\author{
Adam R. Kaul (Durham University)
}

This paper explores the advantages and drawbacks of gainful employment whilst conducting ethnographic fieldwork. Examples are drawn from the author's fieldwork in a heavily visited tourist destination in western Ireland. Whilst there are potential problems that arise due to employment, the benefits are such that it should not be discouraged outright. Moreover, it needs to be discussed as a potential condition of fieldwork. I found that although employment was initially necessary simply to fund my time in the field it became an intensely useful vehicle for gaining access to local knowledge. Employment allows the field researcher to move into and explore emic categorizations of people, and in this case, observe the interactions between permanent residents and tourists. Employment is very rarely discussed in the literature on anthropological methodology, and this paper is intended to continue a growing dialogue about the pragmatic, day-to-day experience of the field.

\section{Introduction}

My doctoral research looks at the way in which tourism is changing and interacting with the performance and meaning of traditional Irish music. I carried out over 14 months of fieldwork in a small, rural Irish village of under 600 people in northwest County Clare. The village was one of a small handful of locales that played a central role in the revival of traditional Irish music from the 1960 s to the 1980 s. During this revival period, a tremendous influx of musicians, Irish music connoisseurs, hippies, and adventurous backpacking tourists made their way to the village for the

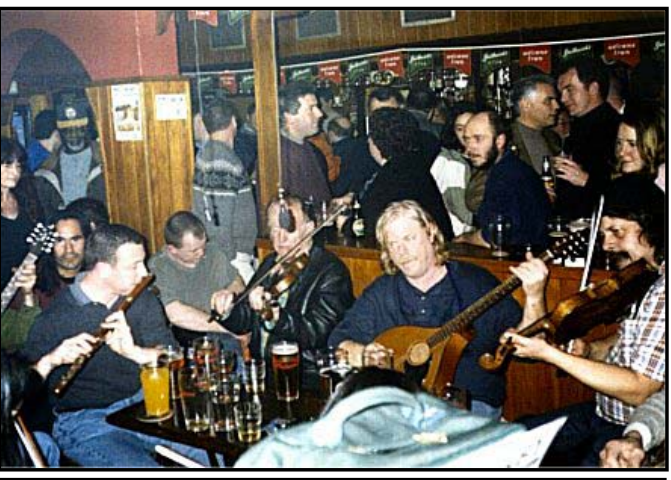

Figure 1: A traditional Irish music session in the village.

music and the craic. ${ }^{1}$ Some returned regularly, and some even stayed. As a result, there is currently a large population of incomers in the village, labelled 'blow-ins' across Ireland, and defined as people who have permanently settled in a locale but who were born elsewhere. Indeed, it is the blow-in population that has now almost completely appropriated the traditional Irish music scene in the village. Moreover, the intense development of the mass tourism industry in the last 20 years has led to a performative and socio-economic consolidation of the music. Questions surrounding

\footnotetext{
${ }^{1}$ Loosely, this means 'fun' or 'entertainment'.
} 
the notions of 'authenticity' and 'tradition' naturally come to the fore, but my concern here is more pragmatic.

Tourist destinations are a relatively new type of fieldsite for anthropologists. I argue that we need to continue to think serendipitously and experimentally about the qualitative ways in which we gain access to such transitory populations. My wife and I were both employed throughout the fieldwork. This turned out to be an extremely productive vantage point for intensive observations. Indeed, my experience is a classic example of what Pelto and Pelto have called 'serendipity, disguised as catastrophe' (1970: 185). I've heard numerous anecdotal stories from social anthropologists about jobs that they had while conducting their fieldwork. However, the issues associated with employment are rarely elaborated upon in any great detail in our methodological discourse, in our publications, or in contexts such as courses on fieldwork methods. As recently as 1996, Lareau was able to contend that 'realistic descriptions of how research data are collected are unusual' (1996: 197). I argue here that not only should we be encouraging a discussion about the very practical, day-to-day experience of doing fieldwork, we should also be adept enough to recognize the opportunities that may emerge from everyday realities, things that initially seem to get in the way of our 'real' work whilst in the field.

\section{Working the field}

When we first arrived in our fieldsite, I was hired at one of the village's three pubs to serve food. Later, I moved behind the bar, serving pints of lager and stout. My wife first worked in the pub as well, but she went on to work in a bed and breakfast and a gift store for the rest of the year. Primarily, we did this because we needed to fund our year of fieldwork. Interestingly, it is grant-funded unemployment in the field that seems to be the most desirable position one can attain. The commonality of this state of being is exemplified by one methodologist who warned that problems may even arise because "the fieldworker often appears to have no apparent "job" or economic role' (Goward 1984: 113). The paucity of discussions about employment in the literature leads to a number of important but unanswered questions: is employment an inhibition to conducting fieldwork? Is it somehow unethical? Or can it in fact be 'used' in any productive way?

My notes from the first few months in the field are riddled with irritated complaints and worries about my employment:

\section{August 2002 [two months into the fieldwork]}

I've been lamenting (ad nauseum) the fact that I've worked so much this summer. I have worked a lot more than most anthropologists would ever want to do for their first few months in the field. That's for sure. Most people might try to get some sort of grant to support them for the duration of their fieldwork. They might consider working (and getting paid for their work) somehow distasteful and even unethical. Mostly, I would imagine most fieldworkers would consider my summer half-ruined because I've spent half of the summer doing brainless work serving plates of food to complaining tourists instead of 'getting out there' interviewing people, doing surveys, blah blah blah... It's completely exhausting. It totally ruins me... I'm usually too tired to bother writing anything after a shift or even in the morning before a shift. I seem only to be able to write much on my days off. And even today, it took me most of the day just to 
rest up from the four days that I worked this weekend. It's only now that I have the energy and the inclination to write... I should just quit and get this over with. I could devote all my time to tracking down people, introducing myself, talking to them, getting interviews, doing the touristsurveys. It's very tempting.

Earning wages from a local establishment initially presented me with what I saw at the time as two major dilemmas. First, I wondered if I was bending any ethical guidelines concerning my involvement with local peoples. To my knowledge, it is not unethical to be gainfully employed in the field, although it is not uncommon for anthropologists to pointedly state that any work they did in the field was done for free (cf. Salazar 1996: 12). The implied subtext in these kinds of statements is that it is in fact unethical, or at least undesirable, to receive money from your informants because being employed compromises one's supposedly 'objective', scholarly position. Secondly and more pragmatically, I felt that my employment was taking me away from my 'real' work in the village: conducting interviews and the like.

The pub I worked in is a large one which can easily host well over 300 tourists at any given

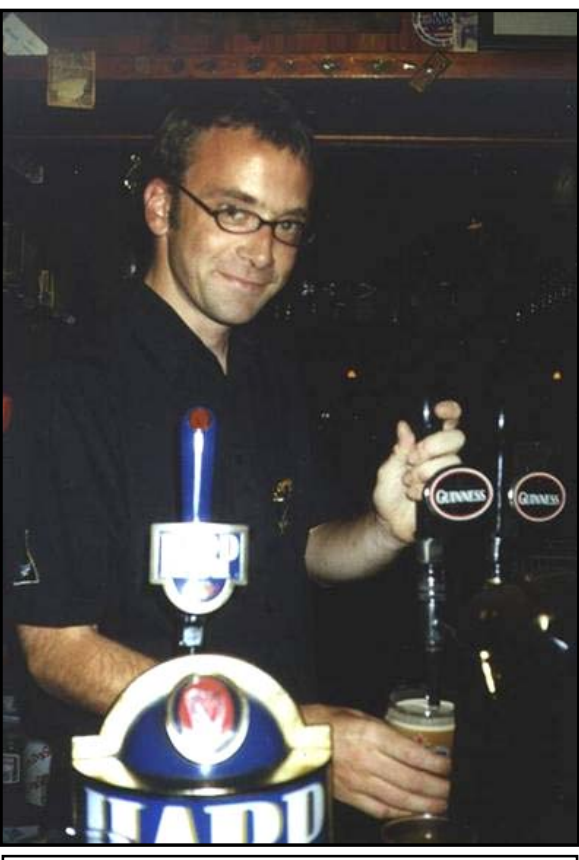

Figure 2: The ethnographer as employee. time. And since we arrived at the height of the tourist season, the work was initially exhausting. The shifts were normally ten hours a day, running through large crowds of tourists in a dark, hot pub. In fact as my fieldnotes indicate, by the end of the first summer, I was so frustrated that I was prepared to quit my employment. For various reasons, I did not quit the job, and I remained employed at the same pub throughout my fieldwork.

The work shifts were long and exhausting primarily because it was the 'tourist season'. By the autumn, the crowds abated, there was less pressure from my employers to take every shift available, and I found myself with all the time I needed to carry out interviews, participant observation (in other contexts), and other forms of 'data collection'. More importantly however, I realized that by being employed in the service industry, I had been closely mirroring local behaviour, and thereby conducting a kind of intensive 'participant observation'. The tourist industry in Ireland, like in many tourist destinations, is highly seasonal. The primary income for most villagers derives from the tourist industry, and therefore, the initial busyness which seemed never ending, in fact had to do with the seasonal nature of work and life in general in the village.

Moreover, our employment in the field placed us in clearly understood emic roles. Many 'working-tourists', particularly those who gain employment as unskilled service-industry workers, pass through tourist destinations to work for a month or two during the busy season. They are what Uriely has cumbersomely called 'noninstitutionalized working tourists' (2000: 3). These workers are more akin to touristswho-work than travelling professionals, and use temporary employment as a means to continue their tourist explorations of a country or a region. On the day that my wife 
and I arrived, the first people we met were our new housemates, and barring one exception, every one of them fit into the category of 'travelling workers'. Their national origins reveal the international nature of this categorization: America, Australia, Sweden, and the Czech Republic. Leisure and work are oftentimes considered diametrically opposed to one another in the literature on tourism. As Graburn famously wrote, 'our conception of tourism is that it is not work' (1989: 22). For that reason, I was quite unprepared for this introduction to social life in a small village in western Ireland. Although admittedly I was surprised by this at first, I quickly came to realize that this working situation was not uncommon. An Irish Independent reporter recently wrote that all across Ireland 'Irish hospitality is now being doled out in bars, hotels, and B\&Bs by non-nationals' (Collins 2002: 4). It was a phenomenon worthy of my attention. Furthermore, being a 'working tourist' brings the newcomer into a circle that is interactively closer to the 'local' than the 'standard' tourist, but as I was to learn later, in the emic terminology, they are still both types of 'tourist'. At first, my wife and I fitted neatly into this category even though we were very open about our intentions to stay for a full year to 'study the traditional music and the tourists'.

In September of 2002, after two and a half months in the field, we signed a ninemonth contract to rent a house for the winter, and by the end of September, the tourist season finally began to subside. At the same time, many working tourists began to leave as the season got quieter. And it was at that point that we both noticed a palpable change in people's behaviours towards us. We soon realized that our continued presence, bolstered by the fact that we'd rented a house for the winter, meant that we were committing ourselves to staying. The winters are quiet with few tourists around. They are cold and rainy, and there is very little employment to be had. Staying through the winter implies that one is on some level making a greater commitment to the community than a 'working tourist'. One is not simply there to benefit from the financial gain that can be enjoyed during the busy summer months. In other words, it is implied that one's motivation for being there has more to do with the community itself, and only secondarily with the work. It brings the newcomer into a closer level of inclusion, and one starts to be labelled as a 'blow-in'.

After we didn't leave, we noticed that people started opening up to us and taking us a bit more seriously. Of course, this also had to do with the fact that the tourist season was over and that people had more time in general. But there was a subtle change in our social status. The local population has become so used to the transient nature of the tourists, and the semi-transient nature of working-tourists, that sometimes they no longer invest intense emotional energy in people unless they stay for longer periods. This was reiterated in the second summer 'tourist season' when we recognized the qualitative difference between our status as (albeit new) blow-ins and the 'working tourists' that began to arrive along with the more stereotypic, short-stay, 'mass' tourists. Observations like these are not merely reflections of the ethnographer's level of involvement in a community. As Paerregaard has pointed out, occupying and passing into various emic categorizations in a society through our local interactions allows the ethnographer to 'examine not only how the people studied by the anthropologist classify non-natives but also how they conceptualise themselves' (2002: 321).

We also found that there was an intense work-ethic in the village. The social emphasis on the concept of work in Ireland has been pointed out by others (Salazar 1996). We found that one gained respect by being honest in one's relationships, and by working 
hard. For some 'working tourists' who were only planning to stay in the village for a short period, it was unnecessary to create a good impression through work behaviours. In a few instances, these 'working tourists' took exploitative advantage of their positions by doing as little work as possible, or in one example, by blatantly stealing from the employer. Conversely, the employers occasionally took advantage of their temporary labourers by requiring them to work long hours doing menial jobs. The explicitly temporary relationships between these 'working tourists' and their employers in other words allowed for mild exploitation by both parties. But of course we had a vested interest in creating good relationships, so we did work very hard through that first summer. This gained us respect amongst our fellow employees, our employers, and importantly, it gained us a positive reputation in the village. One day about two months into my fieldwork, it suddenly struck me that, through my workrelated activities, I'd 'gained rapport', that Holy Grail of ethnographic fieldwork.

Most importantly of course, in a village with three pubs, a 'community centre', a church, and no other social outlets, employment provided quick and intense access to the local social world. Firstly, being a member of a staff of employees provided instant acquaintances. In many ways, I felt that I didn't have one 'gate-keeper'. I had a whole pub full of 'gatekeepers'. Secondly, since the pubs were the spaces in which most of the village's social life occurred, working behind the bar instead of drinking in front of it became an incredibly productive vantage point for getting to know the locals, their relationships with each other and with the tourists. Thirdly, knowledge of local kinship and friendship networks then becomes part of the work-knowledge that one acquires when serving locals who enact a complex 'rounds system' when drinking (Cassidy 1995). Also, since the pubs are natural meeting places, bar-staff act as messengers for the villagers. 'Have you seen... ?' was a daily question posed to bar staff. Those who are deemed 'good' barmen not only know their job well, they know the community well. As a subtext to my training as a barman then, the intricacies of local kin and friendship networks were explicitly pointed out to me by fellow staff members. After 'closing time', the staff always sat down and waited for the 'punters' to finish their drinks and leave. Rituals like these were often conversationally peppered with local gossip, which were necessarily preceded by lengthy explanations of local social relations. While on one level this was simply gossip, it was also a realm of knowledge that was essential in order to serve better the local clientele. Being employed at the pub then, made learning these things an implicit requirement. I would most likely have learned the intricacies of the village kin and friendship networks had I not been employed, but certainly not as quickly, and I imagine, not as thoroughly. Finally, employment gave me special access to the physical 'backstages' of the pub, access that is carefully guarded, as it is in any business. To use a small example of how useful this was, discourses about tourists are different in the kitchen ('backstage') than in the bar area ('front stage'). Similarly, my wife's role as a B\&B worker and a sales clerk at a gift shop provided me with a rich secondary access to other aspects of the tourist/resident interaction and other 'backstage' areas.

Work also gave me the opportunity, a grand excuse one might say, to talk with countless tourists about their holidays and their impressions. Metaphorically and physically, it placed me directly in the path of the tourists. Upon hearing my American accent, they were often as curious about me as I was about them, and discussions about my research interests were more often elicited from the tourists themselves. I found that tourists were more than willing to talk about their impressions gleaned from their holiday experiences. My vantage point allowed me to 
(indeed, forced me to) constantly observe the interaction between tourists and residents - and since the pub is where most of the traditional music sessions are played - between tourists and the sessions of traditional Irish music.

I scratched down a lot of abbreviated notes while working. Indeed, a brief scan of my field notes reveals the constant observational opportunities that employment offered. Again, I might have made similar observations if I hadn't been employed, but my role as a server and barman placed me in a position where I was 'forced' to constantly observe and think about the interaction between the locale and the transient tourists passing through it. The following vignettes, from January $22^{\text {nd }}$, seven months into the fieldwork,

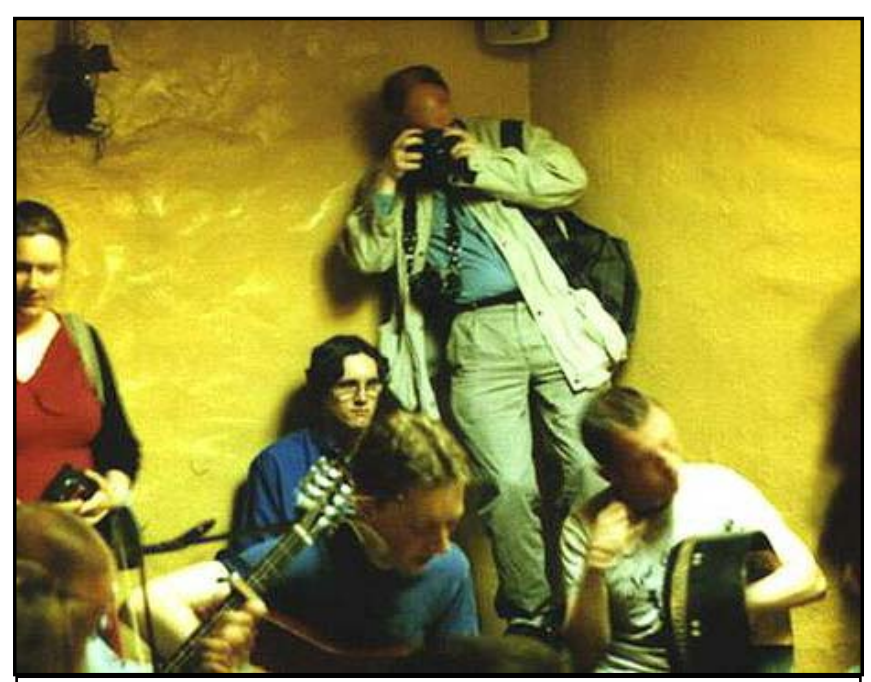

Figure 3: The tourist 'consumption' of the session. are common examples of my work-related observations. The first vignette says something about the seasonality of the locale's tourism, and shows how work itself becomes a measurement of time for my fellow pub employees:

I worked Saturday and Sunday, during the day. Saturday, we had an enormous crowd in the pub. A big group of French tourists had planned to come through, $91 \mathrm{in}$ all. They were travelling in a huge motorcade of minibuses, if that can be believed. They were a fine crowd to be honest, but during the same rush of customers, we also got three other buses: one had 35, another had 28, and a smaller bus of 15 came in. It was July all over again. That was the joke of the day: it went from January to July and back to January again within 3 hours. Time is marked by crowds... Time is also marked by the food people order-the nature of it and the sheer quantity. ('We did 200 people today within four hours'. 'We only did 56 meals tonight'.)

Later, in the same entry, I expanded upon a brief note (that I'd written down in a notebook while working) about the nature of 'loners' on coach tours:

Sunday was steady, but not a killer day of work. I had a thought on Sunday, one that - I suppose-has always been latent in my observations, but never fully expressed. It occurred to me while another bus tour rolled in (we got two that day). It was a mid-sized group of around 30 people, and characteristically, there were various types of people on the bus. You had a few groups of younger people sitting a large table, chatting away... There were also a number of smaller groups-couples or threesomes. Finally, there are always a few people who sit alone. Sometimes, these loners eat quickly and move out onto the street to snap some pictures. Sometimes, they sit at the bar and talk with the locals. But more often than not, they sit alone, watching. They watch us staff. They watch the locals drinking their coffee or their pints, and they watch the other members of their tour group. They are outsiders. I don't know if it's a difference in character or a difference in context that makes them stand out. They may be a more 'adventurous' type of tourist, one who longs to 
experience [what Edensor calls] 'heterogenous spaces' and 'improvised performances' [2000: 331, 335] rather than the homogenous, controlled environment that a bus-tour provides, but somehow found themselves taking the packaged tour. Or maybe the context is one in which a person-adventurous or not-should not be alone. On these package tours, it seems that one should travel with a gaggle of friends or family.

In retrospect, this is a somewhat simplistic conclusion, an unformed, raw interpretation from direct observation. But my point here is that these particular observations were not only produced while working, but that my experiences would not have been as extensive had I not been employed.

It might rightly be argued that employment causes an ethical dilemma for the fieldworker. Taking money from a potential informant colours one's relationship with undertones of power and privilege. At first, I wasn't entirely comfortable with taking money for the work I did, and wondered whether or not it was entirely ethical. The very brief and general ethical guidelines provided by the American Anthropological Association (drafted in 1998) and the Association of Social Anthropologists available on their respective websites say nothing specific about employment in the field. One possible critique might be that employment reduces our chances at some sort of objectivity. In other words, it might lead us to get unevenly involved in the community. Nevertheless, it has been long recognized that "[t]he dilemma of the fieldworker... is not whether to interfere in the local cultural scene, but how much to interfere' (Pelto and Pelto 1970: 186). What is more, it is true that in some circumstances, our employment prevented us from participating in other ways. There were many instances when I was forced to work while I wanted to attend some other event, and I had to allow my employee role take precedence over my anthropological role. And there were interesting conversations that had to end so that I could serve another customer. But this was the corollary consequence of making a choice about how to 'interfere'.

It is something of a cliché to point out that our positions are 'compromized' in dozens of ways throughout the fieldwork as we build relationships of various sorts. Some of our roles are chosen for us. Ascribed markers like gender, race, ethnicity, religious upbringing, and political views, all come in to play as 'our subjects' objectify us and place us into their own categories. Previously achieved skills and abilities come into play as well. Other roles we create ourselves through our own choices and actions whilst in the field. We must live somewhere, with a host family or by paying rent to a landlord. Friendships are developed and maintained (or sometimes abandoned). As a corollary, conflicts, issues of loyalty and reconciliation, and histories of personal differences become inevitable (Glassie 1995 [1982]: 142). We must engage in work of various sorts in order to carry out our participant observation. Building stone fences and chasing cows from one field to another helped me, in a small way, understand the activities of local farmers. Pulling in nets and 'shooting' lobster pots helped me understand what local fishermen get up to. Employment then, is simply one type, albeit a potentially powerful type, of interaction in the field which may help us gain access to local knowledge.

\section{Conclusions}

Each 'field' differs in countless ways. Depending on the circumstances, employment might damage one's reputation, contradict the social role given to the fieldworker by 
'locals', or seriously hinder fieldwork. In other cases, employment might be impossible due to a lack of specific training in a highly qualified kind of job or a lack of basic cultural overlap with the nature of the work. However, in some field situations like mine where there was enough cultural overlap and the skills of the job were learnable such that employment was possible, it might be an incredibly productive experience. I am not suggesting that the knowledge I gained through my employment could not have been acquired via other means, or in the case of the 'backstage' areas, through second hand descriptions. I am also not pretending that employment during fieldwork is somehow radically new. On the other hand, as 'autoanthropology' (Strathern 1987) becomes increasingly common, the higher degree of cultural overlap will, in future, create more employment opportunities for fieldworkers. Not only do we need to re-examine the changing notion of the 'field', but also the ways in which we inhabit it.

I would simply like to posit here that we need to be more open to discussing the possibility of opportunities like employment as a way to gain quick, deep and sometimes privileged access to our fields. In other words, we need to use common sense to take advantage of the serendipitous opportunities that are presented to us as our 'fields' and the people who occupy them become more complicated. Perhaps more importantly, we need to continue discussing the everyday realities of doing fieldwork in much more detail in the literature, and how they might be used as units of analysis in and of themselves. For the novice, learning how to do fieldwork can be mystifying and daunting, especially since most of us currently learn as we go. More common sense discussions about the pragmatic realities of our experiences and frustrations would help alleviate the doubts of future fieldworkers.

\section{References}

Cassidy, T. M. 1995. A socio-cultural analysis of drinking in Ireland. Anthropology Ireland. 5 (1): 3-12.

AAA. 1998. Code of ethics of the American Anthropological Association. www.aaanet.org/committees/ethics/ethcode.htm.

Collins, L. 2002. Irish 'cead mile failte' is now dispensed by foreigners. Sunday Irish Independent. 4 August: 4.

Edensor, T. 2000. Staging tourism: tourists as performers. Annals of Tourism Research. Vol. 27 (2): 322-44.

ASA nd. Ethical guidelines for good research practice. www.theasa.org/ethics.htm.

Glassie, H. 1995 (1982). Passing the time in Ballymenone: culture and history of an Ulster community. Indiana University Press: Bloomington \& Indianapolis.

Goward, N. 1984. The fieldwork experience: status. In Ethnographic research: $a$ guide to general conduct (ed) R. F. Ellen. Academic Press: London.

Graburn, H.N.N. 1989. Tourism: the sacred journey. In Hosts and guests: the anthropology of tourism (ed). V.L. Smith. University of Pennsylvania Press: Philadelpia.

Lareau, A. 1996. Common problems in fieldwork: a personal essay. In Journeys through ethnography: realistic accounts of fieldwork (eds) A. Lareau, \& J. Schultz. Westview Press: Oxford. 
Paerregaard, K. 2002. The resonance of fieldwork. Ethnographers, informants and the creation of anthropological knowledge. Social Anthropology 10 (3): 319-34.

Pelto, P.J. \& G.H. Pelto. 1970. Anthropological research: the structure of inquiry. Cambridge University Press: Cambridge.

Salazar, C. 1996. A sentimental economy: commodity and community in rural Ireland. Oxford: Beghahn.

Strathern, M. 1987. The limits of auto-anthropology. In Anthropology at home (ed) A. Jackson. London: Tavistock.

Uriely, N. 2001. 'Travelling workers' and 'working tourists': variations across the interaction between work and tourism. International Journal of Tourism Research. 3: $1-8$.

\section{About the author}

Adam Kaul obtained his first degree in anthropology at Minnesota State University at Moorhead in 1996. From there, he matriculated to Northern Illinois University and received an MA in cultural anthropology in 1998. Kaul spent the next three years lecturing at Minnesota State University and Concordia College in Moorhead, Minnesota before pursuing a $\mathrm{PhD}$. In 2004, he completed his doctoral studies in anthropology at the University of Durham in the UK. His thesis is an ethnographic account of tourism, incomers and the traditional Irish music scene in a small village in western Ireland. Adam's primary research interests are in the processual creation of identities, tourism, the anthropology of music, performance, folklore, ethnohistory and ethnoscience. Regionally, he is interested in Ireland, the British Isles, Native America and the American Midwest. Currently, Kaul is a lecturer of anthropology at the University of Durham.

Email: adamrkaul@yahoo.com 